\title{
PERIPHERAL VENOUS HYPERTENSION AFTER THE CREATION OF ARTERIOVENOUS FISTULA FOR HAEMODIALYSIS
}

\author{
Petr Bachledaa ${ }^{\mathrm{a}}$ Zdeněk Kojeckýa, Petr Utíkala ${ }^{\mathrm{a}}$, Petr Dráča , Jiří Hermana ${ }^{\mathrm{a}}$, Josef Zadražil ${ }^{\mathrm{b}}$ \\ a $2^{\text {nd }}$ Clinic of Surgery, Faculty of Medicine and Teaching Hospital, I. P. Pavlova 6, 775 20, Olomouc, Czech Republic \\ ${ }^{b} 3^{\text {rd }}$ Clinic of Internal Medicine, Faculty of Medicine and Teaching Hospital, I. P. Pavlova 6, 77520 Olomouc
}

Received: April 5, 2004; Accepted: June 11, 2004

Key words: Arteriovenous fistula for haemodialysis/Peripheral venous hypertension

The function of an arteriovenous (av) fistula for haemodialysis may be complicated by manifestation of peripheral venous hypertension, which results from the arterial blood flow through the venous system into the periphery of the upper extremity. Its development is most typically caused by a proximal forearm av-fistula, as, in addition to the desirable arterialisation of the subcutaneous venous system of the arm, arterialisation of the venous system of the forearm and the hand may occur and possibly promote the development of venous hypertension, which may in the extreme result in gangrene of the fingers. Awareness of these problems as well as of the necessity of their surgical solution is essential for doctors dealing with haemodialysis.

\section{INTRODUCTION}

Proper creation of a well-functioning arteriovenous fistula for haemodialysis is vital for the future life of patients involved in chronic haemodialysis program. Europe generally prefers autologous subcutaneous fistula. A number of complications may occur after its creation, with venous hypertension being one of them ${ }^{5}$. This is caused by a stenosis or occlusion affecting the central venous system (central venous hypertension) or the so-called peripheral form of venous hypertension occurs, resulting from blood flow into the peripheral venous branch of the fistula ${ }^{1,2}$.

Peripheral venous hypertension is now less frequent than in the 1970s and 1980s, when it occurred as a complication connected with the radiocephalic sideto-side fistula and was caused by a technical mistake in the construction of anastomosis, resulting in stenosis or thrombosis of the central discharge branch of the fistula and inflow of blood into the peripheral venous branch of the fistula. This complication was more frequent as a delayed complication, characterised by the development of a typical stenosis of the central vein app. $2-3 \mathrm{~cm}$ after the anastomosis due to haemodynamic factors. This results in a reversed blood flow, alteration of venous valves and filling of the veins of the periphery of the upper extremity $^{1}$. This type of fistula is now used only rarely, and an end-to-side fistula is preferred. Only central flow is thus allowed, and the occurrence of complications has been considerably reduced.

This complication is currently encountered after the creation of a proximal forearm av-fistula. The fistula is created according to Gracz or one of its modifications $\mathbf{s}^{3,4}$. This causes possible arterialisation of the subcutaneous forearm venous system, manifested by venous hyperten- sion. Complications occur not only in the event of an obstruction in the venous system of the arm, with the blood flow seeking for easier passageways and with distal flow being developed after the valves are altered, but also in the case of normal flow in the subcutaneous venous system of the arm with simultaneous filling of the forearm venous system.

Peripheral venous hypertension is manifested by finger and hand oedema, their limited motility, with the advanced stages being characterised by livid swollen fingers and even the development of venous gangrene.

In most cases, therapy is of surgical nature.

\section{OBSERVATION}

Our clinic's experience with the creation of av-fistulas for haemodialysis dates back to 1968. In terms of av-fistula surgery, we share the catchment area of the Teaching Hospital Olomouc Transplantation Centre, i.e. a population of 1 million. Every year we insert app. 100 fistulas and deal with about 150 av-fistula related complications. We prefer autologous av-fistulas, and in the case of venous system insufficiency we construct the fistulas with GORE ePTFE prostheses.

The average age of the patients involved in regular haemodialytic treatment is increasing. The patients are polymorbid and their arterial and venous systems are not suitable for the creation of a typical radiocephalic end-to-side av-fistula. For the creation of the av-fistula we use the proximal forearm, where we arterialise the subcutaneous venous system according to Gracz by means of a connecting vein to the deep venous system ${ }^{3}$. In unfa- 


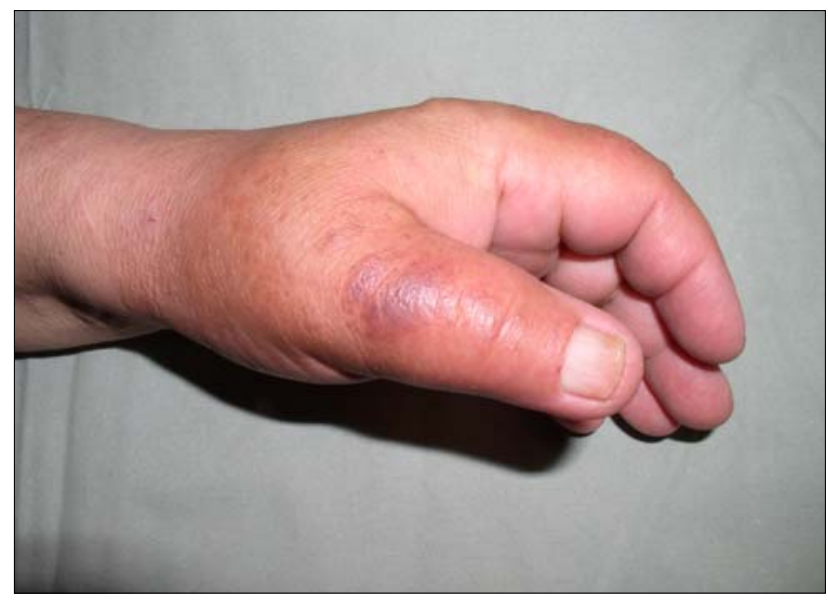

Fig. 1. Hand with manifestations of venous hypertension
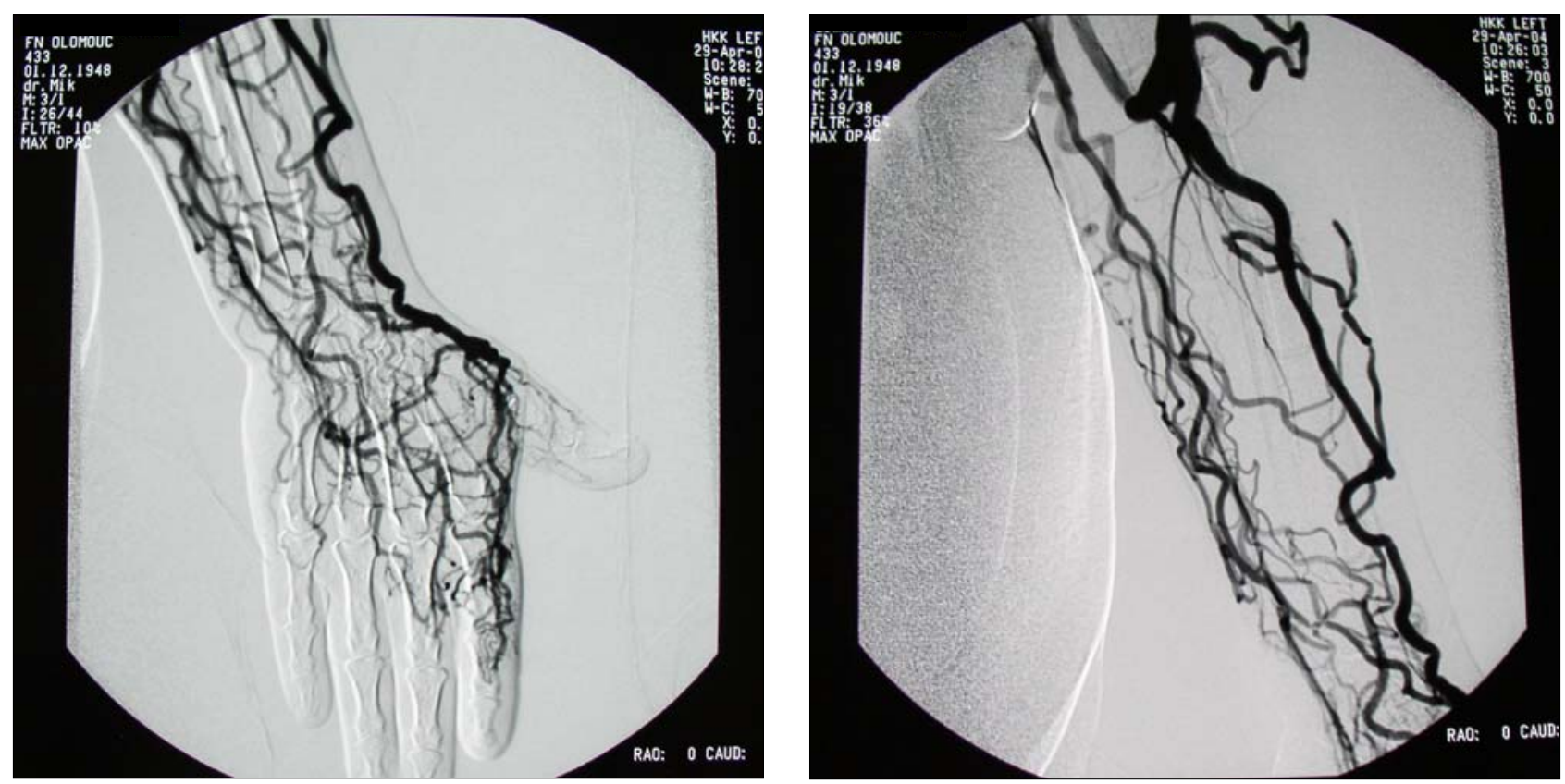

Fig. 2. Angiography
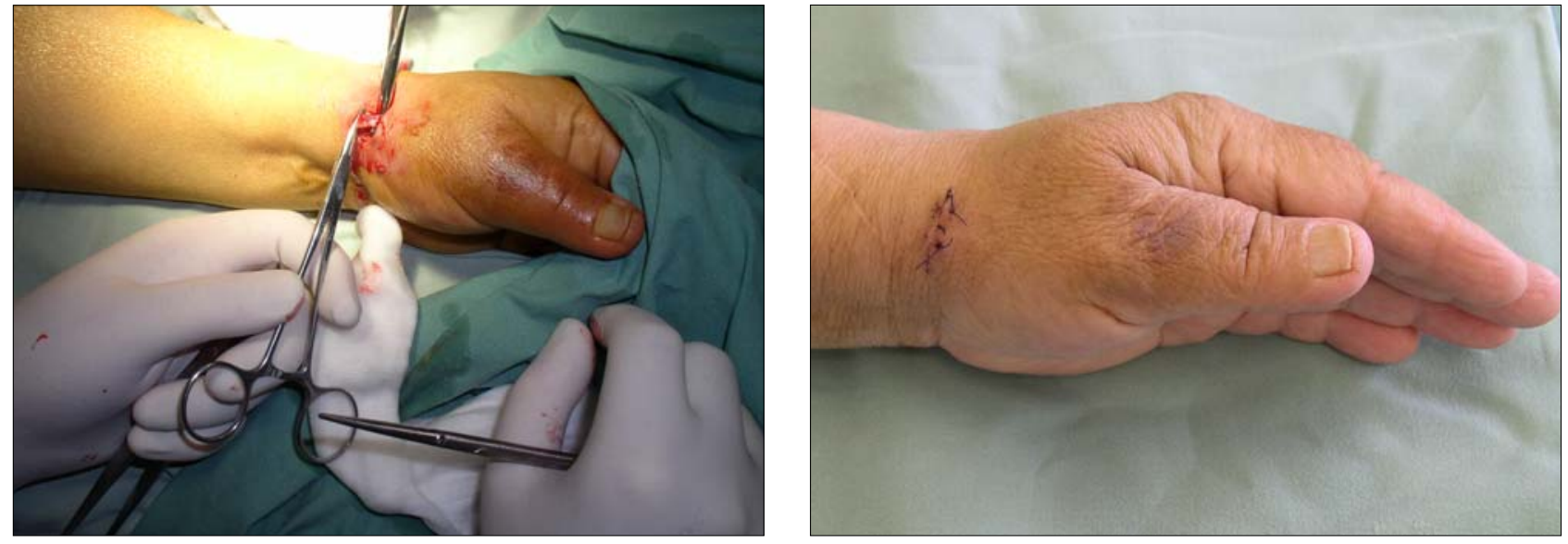

Fig. 3. Ligature of the arterialised subcutaneous vein

Fig. 4. Postoperative finding 
vourable anatomical situations we use a modification of this method ${ }^{4}$.

In the 15-year observation period, a total of 574 proximal forearm fistulas were constructed between 1989 and 2003. Arterialisation of the subcutaneous venous system of the forearm was observed in 32 patients, with only 18 patients showing symptoms of venous hypertension. Hand oedema was observed in 10 cases. 8 patients showed finger oedema and limited motility in various stages including venous gangrene.

Although the clinical findings were typical and verified by means of auscultation and palpation, most patients manifesting the advanced stages underwent angiography and/or, after other methods had become available, colour duplex sonography. The treatment was always of a surgical nature, employing a ligature of the arterialised veins leading into the hand.

Visual documentation: female patient after the creation of a proximal forearm av-fistula according to Gracz, with developed venous hypertension manifested primarily on the thumb. Damage to the central venous outflow system may be ruled out. The patient has not been yet dialysed, and angiography shows no obstructions in the central discharge.

\section{DISCUSSION}

A major part of the literature focuses on central venous hypertension ${ }^{7,8}$. Problems connected with peripheral venous hypertension are neglected in the published works, and patients with its manifestation often undergo nonsurgical symptomatic therapy ${ }^{1,2,9,10}$.

The development and manifestation of peripheral venous hypertension depend on the anatomy of the subcutaneous venous system as well as the type of surgery. When inserting a proximal forearm av-fistula it is necessary to use for the anastomosis the so-called perforating vein connecting the subcutaneous and deep venous systems $^{3,4}$. Its employment represents two advantages: the forearm subcutaneous venous system itself is not used for the anastomosis and, at the same time, the connection with the deep venous system is broken. If a subcutaneous vein is used for the anastomosis, it is necessary to find and ligate the perforating vein, as it is the most frequent passageway through which the deep venous system is filled, causing upper extremity oedema. Another key factor is the anatomy of the subcutaneous venous system of the forearm. The complication is caused by a combination of high blood inflow and insufficient number of inherent anastomoses of the subcutaneous venous system of the periphery of the upper extremity.
In terms of differential diagnosis, it is necessary to distinguish another complication of the av-fistula for haemodialysis, which induces a similar picture (without the oedema) - a hyperfunctional fistula. This is not caused by hypertension in the venous system, but by limb ischemia due to the hyperfunction of the fistula and insufficient filling of the arterial system distal to the fistula ${ }^{6}$.

The clinical findings of the complication start with oedema of one or more fingers (the thumb is often affected). The oedema may affect the whole hand and forearm. The more developed stages are manifested by livid coloration of the fingers, dermonecrosis and even venous gangrene of the fingers.

Additional examination is easy, given the awareness of the problems. Physical examination, palpation and auscultation will indicate the direction of blood flow. The final diagnosis will be established by means of colour duplex sonography and some form of angiography.

Treatment is of a surgical nature and requires targeted ligature of arterialised veins leading into the hand. If arterialisation of the deep venous system is identified as the cause, the fistula must be cancelled. Only mild forms of the complications, mostly demonstrated by oedema, may be treated by positioning of the limb and employment of bandages.

\section{REFERENCES}

1. Kindhäuser V, Kottmann F. (1979) Die operative Korrektur der venösen Insuffizienz nach arterio-venöser Fistel zur Hämodialyse. Chirurg 50, 359-363.

2. Nghiem DD. (1987) Angioaccess by reverse brachiocephalic fistula. Am J Surg 153, 574-575.

3. Gracz KC, Ing TS, Soung LS. (1977) Proximal forearm fistula for maintenance hemodialysis. Kidney Int, 71-4.

4. Utíkal P, Bachleda P. (1996) Naše zkušenosti se zakládáním arteriovenózních spojek v loketní jamce. Rozhl Chir 75, 83-87.

5. Haimov M, Baez A, Neff M, Slifkin R. (1975) Complication od arteriovenous fistulas for hemodialysis. Arch Surg 110, 708-712.

6. Bachleda P, Zadražil J.(1993) Die Ischämie der oberen Extremität als Komplikation einer AV-Fistel zur Hämodialyse. Acta Univ Palacki Olomuc 135, 93-94.

7. Kojecký Z, Utikal P, Sekanina Z, Köcher M, Buriánkova E. (2002) Venous hypertension following average arterio-venous fistula for haemodialysis. Biomed Pap Med Fac Univ Palacky Olomouc 146, 77-79.

8. Landwehr P, Lackner K, Gotz R. (1990) Dilatation und ballonexpandierbare Stents zur Therapie zentralvenöser Stenosen bei Dialysepatienten. Fortschr Roentgenstr 153, 239-245.

9. Swayne LC, Manstein C, Somers R, Cope C. (1983) Selective digital venous hypertension: a rare complication of hemodialysis arteriovenous fistula. Cardiovasc Intervent Radiol 6, 61-62.

10. Irvine C, Holt P. (1989) Hand venous hypertension complicating arterio-venous fistula construction for haemodialysis. Clin Exp Dermatol 14, 289-290. 